\title{
Corpus-based analysis of the collocational profiles of the terms denoting the mentally challenged
}

\author{
Liana Markelova (Pskov)
}

\begin{abstract}
The present study aims to trace the evolution of public attitude towards the mentally challenged by means of the corpus-based analysis. The raw data comes from the two of the BYU corpora: Global Web-Based English (GloWbE) and Corpus of Historical American English (COHA). The former is comprised of 1.8 million web pages from 20 Englishspeaking countries (Davies/Fuchs 2015: 1) and provides an opportunity to research at a crosscultural level, whereas the latter, containing 400 million words from more than 100,000 texts ranging from the 1810 s to the 2000s (Davies 2012: 121), allows to carry on a diachronic research on the issue.

To identify the difference in attitudes the collocational profiles of the terms denoting the mentally challenged were created. Having analysed them in terms of their semantic prosody one might conclude that there are certain semantic shifts that occurred due to the modern usage preferences and gradual change in public perception of everything strange, unusual and unique.
\end{abstract}

\section{$1 \quad$ Introduction}

Public attitude towards different groups of the mentally challenged has always been a controversial issue. Although in the past mental health problems without exception were something to be ashamed of (Hughes 1988, Høyersten 2007, Sontag 1978), nowadays there is a considerable shift towards accepting some of the problems and more than frowning upon the others.

The present study focuses on the evolution of attitudes towards the mentally challenged. The aim is to find out the diachronic and synchronic differences in the public attitude and stereotyping towards the mentally challenged and to figure out if these differences depend on the type of the illness.

Since the principle of the corpus analysis holds that invented examples cannot be treated as primary data (Hanks 2013: 10), the Brigham Young University (BYU) corpora were used for that purpose. The corpus analysis made it possible to create the collocational profiles of the most frequently used lexical items denoting the mentally challenged people or, in cases when there is no term for them, mental disorders. Such profiles not only facilitate the understanding 
of the usage restrictions of words, but they also contribute to the ultimate understanding of how words change their meanings or acquire new shades.

Therefore, to reach the aim this study was divided into several parts: the first part The data will concern itself with the description of the data sources and the methods of data collection and processing. The second part Theoretical background will dwell upon the role of corpusbased analysis in linguistics shedding the light on some paramount notions in corpus linguistics. The third and the most important part of this study Corpus-based analysis of the mentally challenged will turn to the corpus-based analysis of the collocational profiles of the lexical items denoting the mentally challenged people. This will involve looking into the way semantic prosody of these items differs synchronically and diachronically. Finally, the last part Conclusions will deal with the outcome of the study.

\section{The data}

The mental disorders that people frequently suffer from were chosen from the nomenclature of mental disorders, suggested in Diagnostic and Statistical Manual of Mental Disorders (DSM-5 2013), which is considered to be a standard classification of mental diseases used by mental health professionals. The list of the mental disorders was comprised of 18 mental illnesses that fall into groups each varying by the origin / nature of the disease, and, therefore, includes:

1. acute stress disorder (trauma- and stressor-related disorders);

2. alcohol intoxication (substance-related disorders);

3. Alzheimer's disease (neurocognitive disorders);

4. anorexia (feeding and eating disorders);

5. autism (neurodevelopmental disorders);

6. bipolar disorder (bipolar and related disorders);

7. cretinism (developmental disorders);

8. dementia (neurocognitive disorders);

9. down's syndrome (developmental disorders);

10. drug abuse (substance-related disorders);

11. obsessive-compulsive disorder (obsessive-compulsive and related disorders);

12. panic disorder (anxiety disorders);

13. paranoid personality disorder (personality disorders);

14. Parkinson's disease (neurocognitive disorders);

15. paedophilia (paraphilic disorders);

16. psychopathy (antisocial personality disorders);

17. schizophrenia (schizophrenia spectrum disorders);

18. shopaholism (impulse-control disorders). 
profiles of the terms denoting the mentally challenged

However, in this paper the analysis of only six groups of the mentally challenged (suffering from alcohol intoxication; Alzheimer's disease; anorexia; autism; bipolar disorder; schizophrenia), each varying in nature of the disorder, will be presented to illustrate the changes in attitude and its dependence on the type of the disease.

Two closely related BYU corpora were chosen for the analysis: GloWbE (Global Web-Based English features the corpus of 1.9 billion words from 1.8 million web pages across 20 English-speaking countries) and COHA (Corpus of Historic AmE comprised of 400 million words from over 100,000 texts dating from the 1810s to the 2000s).

Nearly 60 percent of the GloWbE corpus is taken from informal blogs, the rest of it comes from a wide variety of more formal genres and text types, such as newspapers, magazines, company websites, etc. (Davies/Fuchs 2015: 1). GloWbE permits to research on a wide variety of Englishes (six Inner Circle, where the US and the UK corpora have the largest size (both about 386 million words), and 14 Outer Circle countries, where the corpora have 40 million words for each country) and is universally used to investigate lexical, morphological, syntactic and meaning variations across them. It serves as an important tool to elicit cultural peculiarities too. In this paper GloWbE provides an insight into the way public attitude towards the mentally challenged develops across various English-speaking countries synchronically.

COHA in its turn allows to see the frequency of specific words and phraseological expressions and the way it can change over certain time periods. The corpus contains texts of various types, taken from fiction, popular magazines, newspapers and non-fiction books and is well balanced by genre in each decade starting from the 1810s and up to the 2000s (Davies 2012). COHA provides enough evidence to compare the morphological structure and meaning of words which allows to recognize new morphological patterns and semantic shifts in American culture and society. As far as the concordance lines in COHA are concerned, the word distribution gives an opportunity to trace the change in public attitude (e.g. attitude towards the mental disorders) over time, i. e. diachronically.

Besides searching, both in GloWbE and in COHA there are also a number of other techniques allowing for a more thorough analysis, such as, for instance, chart option which helps to visualize the overall frequency, or KWIC which gives more context for a keyword.

\section{Theoretical background}

Corpus-based analysis provides exceptional opportunities to research the peculiarities of word distribution by giving evidence on such parameters as, for example, frequency and close proximity.

Corpora consist of texts which being results of language usage indicate close ties between lexis and syntax and therefore are bound to deal with collocations, frames and semantic prosody.

To be recognised as a collocation a phrase has to consist of a collocate and a base, which together are treated as an almost separate semantic unit (Granger/Meunier 2008: 56). Collocations occur in frames, that, being "certain kinds of structured background 
information" (Fillmore 2003: 263), contribute a great deal not only to the word understanding but also to its distributional specifics and the emergence of collocational patterns (Granger and Meunier 2008: 51).

Every word, even being neutrally charged, is likely to have positive or negative colouring due to its word distribution and as Putnam states environmental factors play a substantial role in determining meaning (Putnam 1975). Having been first noticed by John Sinclair (1987), semantic prosody is "the spreading of connotational colouring beyond single word boundaries" (Partington 1998: 68). Thus, if the collocates of the word in question are mostly negatively or positively charged or occur in frames of certain nature, the word is liable to have a negative / bad or positive / good semantic prosody respectively. It is true, however, that the words tend to maintain their regular semantic prosody and, as Michael Stubbs points out, some words have a negative prosody, a few - a positive prosody, and the majority of words are neutral (1996).

Since the following analysis is concerned with attitude and stereotyping, it is important to differentiate between these two notions. An attitude is an evaluative judgment of an object, a person, or a social group (Crano/Prislin 2008). Attitudes are subjective, liable to change and do not usually pre-exist. A stereotype, in its turn, is " [...] a fixed, over generalized belief about a particular group or class of people" (Cardwell 1996: 213). The majority of stereotypes are negative and difficult to eradicate.

Based on other researches, such as for example 'Attitudes towards English in Norway: A corpus-based study of attitudinal expressions in newspaper discourse' by Anne-Line Graedler (2014), linguistic realisation of attitude is manifested through various ways of expression. In this research the main focus of the analysis is on the manifestation of attitudes through the adjectival collocates.

\section{Corpus-based analysis of the mentally challenged}

This part of the study features the analysis of the collocational profiles of six groups of the mentally challenged, which were mentioned in section 2. The data, and focuses on the evolution of attitudes towards these categories of people.

In this study the adjectival collocates, since they are generally more opinionated and therefore allow to see if a portrayal is biased, of the terms denoting the people suffering from the mental disorders were analysed to find out the public attitude towards them. In the majority of cases the node word was the term denoting the mentally challenged suffering from a particular disorder but in cases with Alzheimer's disease and bipolar disorder where there is no common term for the diseased, the name of a mental disorder was used instead. Top 10 left frequency adjectival collocates in GloWbE and the most frequently used collocates in every decade in COHA of the above-mentioned node words were then studied to create the collocational profiles and to find out the shifts in semantic prosody. Despite the fact that frequency rate alone cannot define a collocation, the most frequently used collocates on the list were still chosen for the analysis since they are most likely to relate to the most common portrayal of the mentally challenged people and to ensure the intersubjectivity of the research. In the following analysis, the semantic prosody is determined introspectively on the basis of 
profiles of the terms denoting the mentally challenged

the analysis of the context of the collocations. Furthermore, duplicate examples were omitted. The collocates (together with their frequency within the actual number of citations and semantic prosody) were listed in tables in order of significance. The overall number of analysed collocations in this research is 163 , the overall number of analysed citations is 579 .

\section{Alcohol intoxication}

GloWbE

NODE word: alcoholics (total number of citations: 240)

The plural form of the node word was chosen to avoid confusion between numerous collocations containing alcoholic as an adjective and alcoholic as a noun while searching.

\begin{tabular}{|c|c|c|}
\hline $1^{\text {st }}$ left frequency & Adjectival collocates of alcoholics & $\begin{array}{l}\text { Good/bad semantic } \\
\text { prosody }\end{array}$ \\
\hline 31 & other & good \\
\hline 13 & chronic & bad \\
\hline 12 & raging & bad \\
\hline 10 & unemployed & bad \\
\hline 8 & male & neutral / bad \\
\hline 7 & sober & good \\
\hline 5 & female & bad \\
\hline 4 & functional & bad \\
\hline 3 & hopeless & bad \\
\hline 3 & homeless & bad \\
\hline
\end{tabular}

Table 1: Adjectival collocates of alcoholics (GloWbE)

COHA

NODE word: alcoholics (total number of citations: 176)

\begin{tabular}{|c|c|c|c|c|c|}
\hline $1840 \mathrm{~s}-1890 \mathrm{~s}$ & $\begin{array}{l}1^{\text {st }} \text { left } \\
\text { frequency }\end{array}$ & $\begin{array}{l}\text { Good/bad } \\
\text { semantic } \\
\text { prosody }\end{array}$ & $1990 s-2000 s$ & $\begin{array}{l}1^{\text {st }} \text { left } \\
\text { frequency }\end{array}$ & $\begin{array}{l}\text { Good/bad } \\
\text { semantic } \\
\text { prosody }\end{array}$ \\
\hline \multirow[t]{6}{*}{ no data } & & & the $1900 \mathrm{~s}$ & & \\
\hline & & & chronic & 1 & bad \\
\hline & & & $\begin{array}{l}\text { the 1910s- } \\
1920 \mathrm{~s}\end{array}$ & & \\
\hline & & & high & 6 & neural / bad \\
\hline & & & typical & 1 & bad \\
\hline & & & ruddy-faced & 1 & bad \\
\hline
\end{tabular}




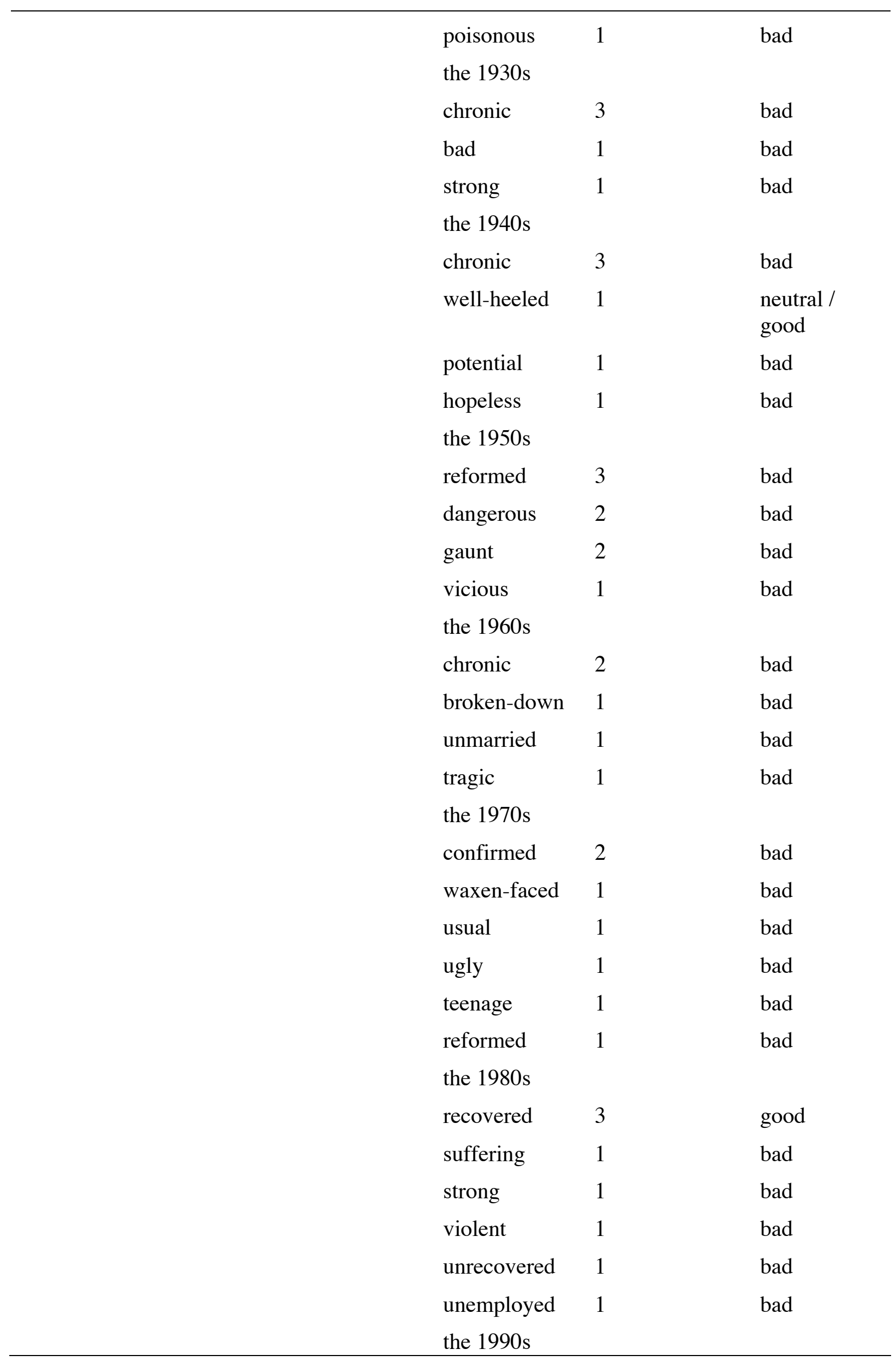


profiles of the terms denoting the mentally challenged

\begin{tabular}{lll}
\hline bad & 2 & bad \\
abusive & 1 & bad \\
wife-beating & 1 & bad \\
wicked & 1 & bad \\
reformed & 1 & bad \\
the 2000s & & \\
dedicated & 2 & bad \\
thickening & 1 & bad \\
spiteful & 1 & bad \\
potent & 1 & bad \\
penniless & 1 & bad \\
homeless & 1 & bad \\
furtive & 1 & bad \\
drunk & 1 & bad \\
dangerous & 1 & bad \\
chronic & 1 & bad \\
\hline
\end{tabular}

\section{Table 2: Adjectival collocates of alcoholics (COHA)}

According to the manual of mental disorders (DSM-5 2013: 498), alcohol intoxication is more tolerated for males. Thus, National Survey on Drug Use and Health in the USA states that 16.6 million adults aged 18 and older had an alcohol use disorder in 2013 (NSDUH 2015). This includes 10.8 million men (9.4 percent of men in this age group) and 5.8 million women (4.7 percent of women in this age group). Moreover, GloWbE (see Table 1) provides 8 male alcoholic and 5 female alcoholic citations, thus indicating that although female alcohol abuse is not quite on par with the male alcoholism, one cannot but notice that the percentage of female alcohol abusers is steadily growing. One more detail is worth mentioning here: judging by the citations listed in GloWbE, male alcoholic has either neutral or negative semantic prosody, e. g. (1), whereas female alcoholic is a strictly negative concept there, e.g.

(2) and (3):

(1) Female alcoholics are likely to perceive more censure and feel more shame than male alcoholics will.

(2) Beckman reported that a group of white female alcoholics believed that low self-esteem was the major cause of their drinking.

(3) There are as many violent female alcoholics as there are violent male alcoholics.

(GloWbE) 
While GloWbE provides the evidence that the image of an alcohol abuser is highly stereotyped across the world, e. g. (4), (5) and (6):

(4) Many of my local friends' fathers were raging alcoholics and I learned early in life to avoid them (CA).

(5) The streets are filled with unemployed alcoholics (BD).

(6) At the very bottom of the social ladder, you find hopeless alcoholics and drug addicts $(\mathrm{NG})$;

(GloWbE)

thus, proving that alcoholism is a severely stigmatized mental disorder (as stated in Schomerus et al. 2010), COHA (see Table 2) indicates that alcoholism has been an issue for quite a while. There is not enough evidence during the $1850 \mathrm{~s}-1890 \mathrm{~s}$, since alcoholic was used only as an adjective at that time, e. g. (7) and (8):

(7) Two were small groceries, in which the vilest alcoholic compounds were sold at a bit (ten cents) a glass. (the 1860s);

(8) But the peculiarity of this stimulus, and especially of the liquor-saloons, is, that moderation is almost unknown among the working classes, wherever the extreme alcoholic beverages are employed. (the 1880s);

(COHA)

However, there are already 7 citations recorded during the 1920s-1930s and, possibly, that might be because of the Prohibition in the USA (1920-1933).

In sum, COHA creates a dismal image of the alcohol abusers (homeless, penniless, brokendown, hopeless, wife-beating alcoholics) and underlines that even though nowadays there are various facilities and opportunities for such people (recovered, reformed alcoholics), the attitude towards them has not changed much: among the analysed collocates only 2 collocates have neutral or good prosody.

\section{Alzheimer's disease}

GloWbE

NODE word: Alzheimer's disease (total number of citations: 365 )

\begin{tabular}{lll}
\hline 1 st left frequency & $\begin{array}{l}\text { Adjectival collocates of Alzheimer's } \\
\text { disease }\end{array}$ & $\begin{array}{l}\text { Good/bad semantic } \\
\text { prosody }\end{array}$ \\
45 & early-onset & bad \\
34 & late-onset & neutral \\
17 & advanced & bad \\
12 & mild & neutral \\
12 & national & bad \\
11 & severe & bad \\
\hline
\end{tabular}


profiles of the terms denoting the mentally challenged

\begin{tabular}{lll}
\hline 4 (US) & dreaded & bad \\
2 & evil & bad \\
2 & hospitalized & neutral / bad \\
2 (US) & spiritual & bad \\
\hline
\end{tabular}

Table 3: Adjectival collocates of Alzheimer's

disease (GloWbE)

COHA

NODE word: Alzheimer's disease (total number of citations: 21)

\begin{tabular}{lll}
\hline $\begin{array}{l}\text { 1980s-2000s } \\
\text { the 1980s }\end{array}$ & Good/bad semantic prosody \\
$\begin{array}{l}\text { familial } \\
\text { the 1990s }\end{array}$ & 2 & bad \\
full-blown & 2 & bad \\
national & 1 & bad \\
late-onset & & neutral \\
early & 1 & bad \\
the 2000s & & \\
mild & 3 & neutral / good \\
early-onset & 3 & bad \\
early & 2 & bad \\
premature & 1 & bad \\
late-stage & 1 & bad \\
genuine & 1 & bad \\
advanced & 1 & bad
\end{tabular}

Table 4: Adjectival collocates of Alzheimer's

disease (COHA)

Both GloWbE (see Table 3) and COHA (see Table 4) indicate that public attitude towards people with Alzheimer's disease is not stereotyped. The first-mentioned collocates date back to the 1980s. More collocates appeared during the next two decades. This can be easily justified by the development in medical science.

The majority of the collocates indicate various stages and types of the disease (e. g. mild, advanced, early-onset, late-onset). GloWbE also allows to trace one seemingly regional peculiarity: four citations with dreaded were found in the US data, which emphasise the fear that people overcome when being faced with Alzheimer's disease. However, such a peculiarity can hardly be called regional, since Alzheimer's disease is a kind of an incurable for now disease that is feared universally. 
Alzheimer's disease belongs to the pre-senile dementia group and refers to younger age. Therefore, its early-onset is particularly dismal and all related collocates, both in GloWbE and in COHA, have a negative semantic prosody.

In several cases in GloWbE, as well as in COHA, the collocates indicate that Alzheimer's disease is used metaphorically to denote mass confusion, e. g. (9) and (10):

(9) I have likened the mass amnesia afflicting God's people to a kind of spiritual Alzheimer's.

(10)It's Terkel's remedy for what he calls the national Alzheimer's disease possessing us.

(GloWbE)

\section{Anorexia}

GloWbE

NODE word: anorexic (total number of citations: 57)

\begin{tabular}{|c|c|c|}
\hline 1 st left frequency & Adjectival collocates of anorexic & $\begin{array}{l}\text { Good/bad semantic } \\
\text { prosody }\end{array}$ \\
\hline $9(7 \mathrm{~GB})$ & recovered & good \\
\hline $4(3 \mathrm{HK})$ & skinny & bad \\
\hline 3 & typical & bad \\
\hline 2 & creepy & bad \\
\hline 2 & teenage & bad \\
\hline $1(\mathrm{TZ})$ & wretched & bad \\
\hline $1(\mathrm{~GB})$ & unfortunate & bad \\
\hline $1(\mathrm{CA})$ & spiritual & bad \\
\hline $1(\mathrm{~GB})$ & airbrushed & bad \\
\hline 1 (US) & financial & bad \\
\hline
\end{tabular}

Table 5: Adjectival collocates of anorexic (GloWbE)

COHA

NODE word: anorexic (total number of citations: 5)

\begin{tabular}{|c|c|c|}
\hline $\begin{array}{l}1980 \mathrm{~s}-2000 \mathrm{~s} \\
\text { the } 1980 \mathrm{~s}\end{array}$ & $1^{\text {st }}$ left frequency & Good/bad semantic prosody \\
\hline $\begin{array}{l}\text { little } \\
\text { the 1990s }\end{array}$ & 1 & neutral / bad \\
\hline $\begin{array}{l}\text { cigarette-smoking } \\
\text { the } 2000 \mathrm{~s}\end{array}$ & 1 & bad \\
\hline typical & 1 & neutral \\
\hline stick-thin & 1 & bad \\
\hline 90-pound & 1 & bad \\
\hline
\end{tabular}


profiles of the terms denoting the mentally challenged

The image conjured up by the immediate collocates of the word anorexic, both in GloWbE (see Table 5) and in COHA (see Table 6), is quite typical and generally does not trigger off any negative reactions towards the diseased person. The most optimistic portrayal of anorexics appeared to be that created by the citations found in the UK region, e. g. (11) and (12):

(11) A recovered anorexic, she assists in counseling and supporting young women struggling with eating disorders.

(12)I'm sharing this story for two reasons: firstly because I am interested in your opinions, and secondly because the words of the recovered anorexic shared above should bring hope to the loved ones of anyone suffering from an eating disorder.

(GloWbE)

The time period available in COHA (the 1980s-2000s) can be explained by the heyday of modelling, which consequently resulted in many models striving to slim down (skinny, stickthin, 90-pound). Although anorexics do not seem to be frowned upon, they are, nevertheless, either pitied (unfortunate) or often accused of their own problems (cigarette-smoking), and that is the reason why the majority of the collocates still have negative semantic prosody.

A number of collocates indicate that anorexic can be used metaphorically to denote a person facing a shortage of something, e. g. (13) and (14):

(13)For so many years I was a spiritual anorexic. I starved myself, and did not partake of this great banquet the Lord has prepared for me.

(14) Maybe from their point of view, you are going too far in depriving yourself, like a financial anorexic.

(GloWbE)

\section{Autism}

\section{GloWbE}

NODE word: autistics (total number of citations: 36 )

As in the case with alcoholics the plural form of the node word was chosen to avoid confusion.

\begin{tabular}{lll}
\hline $1^{\text {st }}$ left frequency & Adjectival collocates of autistics & $\begin{array}{l}\text { Good/bad semantic } \\
\text { prosody }\end{array}$ \\
5 & functioning & neutral / good \\
2 (US) & high-functioning & neutral / good \\
2 & gifted & neutral \\
1 & undiagnosed & neutral \\
1 & severe & bad \\
$1(\mathrm{~GB})$ & retarded & bad \\
$1(\mathrm{US})$ & impaired & bad \\
\hline
\end{tabular}




\begin{tabular}{lll}
\hline 1 (US) & female & bad \\
1 (US) & famous & neutral \\
1 (US) & disabled & bad \\
\hline
\end{tabular}

Table 7: Adjectival collocates of autistics (GloWbE)

COHA

NODE word: autistics (total number of citations: 3 )

\begin{tabular}{lll}
\hline $\begin{array}{l}\text { 1980s-2000s } \\
\text { the 1990s }\end{array}$ & Good/bad semantic prosody \\
$\begin{array}{l}\text { low-functioning } \\
\text { the 2000s }\end{array}$ & 1 & $\mathrm{bad}$ \\
wellknown & 1 & \\
poor & 1 & neutral / good \\
\hline
\end{tabular}

Table 8: Adjectival collocates of autistics ( $\mathrm{COHA})$

Judging by the collocates (see Table 7 and 8) the people suffering from autism are often perceived as generally functioning (e.g. functioning, high-functioning) and somewhat talented (e.g. gifted, famous, well-known) human beings. Partly this might be explained by the fact that the stigma attached to autism had been greatly reduced by the end of the 20th century with the help of media and medical science, e. g. (15) and (16):

(15)My Grandson is a 5 year old high functioning autistic child, who now is given excellent help, the school he is going to has 1 in every classroom;

(16)It's not to show you how very cool I am, but to highlight that although I am clearly by no means disabled, I am what you would call high functioning Autistic.

(COHA)

The percentage of citations (58.30 percent) found in the US region suggests that considerable attention is paid to the people with autism in the US.

\section{Bipolar disorder}

GloWbE

NODE word: bipolar disorder (total number of citations: 57)

\begin{tabular}{lll}
\hline $1^{\text {st }}$ left frequency & Adjectival collocates of bipolar disorder & $\begin{array}{l}\text { Good/bad semantic } \\
\text { prosody } \\
7 \text { (4 US) }\end{array}$ \\
5 & severe & bad \\
2 & undiagnosed & bad \\
2 & mild & neutral \\
2 & possible & neutral \\
\hline
\end{tabular}


profiles of the terms denoting the mentally challenged

\begin{tabular}{lll}
\hline 2 & untreated & bad \\
1 & significant & bad \\
$1(\mathrm{CA})$ & notorious & bad \\
1 & full-blown & bad \\
1 & early-onset & neutral \\
\hline
\end{tabular}

Table 9: Adjectival collocates of bipolar disorder (GloWbE)

COHA

NODE word: bipolar disorder (total number of citations: 4)

\begin{tabular}{lll}
\hline 2000 s & $1^{\text {st }}$ left frequency & Good/bad semantic prosody \\
early-onset & 2 & neutral \\
undiagnosed & 1 & bad \\
adult & 1 & neutral \\
\hline
\end{tabular}

Table 10: Adjectival collocates of bipolar disorder (COHA)

The collocates provided by both, GloWbE and COHA (see Table 9 and 10), although hinting at the severity of the state (severe, significant, full-blown) and having negative or neutral semantic prosody, do not communicate a stereotyped image. Taking the time period (the 2000s) into consideration one might assume that the tolerance towards people with bipolar disorder is connected with numerous coming-outs of famous people admitting that they suffer from this disease.

However, as the collocates show, untreated and undiagnosed bipolar disorder poses great danger to health, e.g. (17) and (18):

(17) After her son died from untreated bipolar disorder, she became an advocate for giving families more control over the healthcare needs;

(18) Jaroszko said in an interview that a previously undiagnosed bipolar disorder drove him to attempt suicide some years ago.

(GloWbE)

\section{Schizophrenia}

\section{GloWbE}

NODE word: schizophrenic (total number of citations: 259)

\begin{tabular}{lll}
\hline $1^{\text {st }}$ left frequency & Adjectival collocates of schizophrenic & $\begin{array}{l}\text { Good/bad semantic } \\
\text { prosody } \\
111\end{array}$ \\
paranoid & bad \\
7 & diagnosed & bad \\
3 & severe & bad \\
3 & functioning & neutral \\
2 & chronic & bad \\
\hline
\end{tabular}




\begin{tabular}{lll}
\hline 2 & dangerous & bad \\
2 & homeless & bad \\
2 & hallucinating & bad \\
2 & crazed & bad \\
1 & sociopathic & bad \\
\hline
\end{tabular}

Table 11: Adjectival collocates of schizophrenic (GloWbE)

COHA

NODE word: schizophrenic (total number of citations: 64)

\begin{tabular}{|c|c|c|c|c|c|}
\hline 1930s-1980s & $\begin{array}{l}1^{\text {st }} \text { left } \\
\text { frequency }\end{array}$ & $\begin{array}{l}\text { Good/bad } \\
\text { semantic } \\
\text { prosody }\end{array}$ & 1990s-2000s & $\begin{array}{l}1^{\text {st }} \text { left } \\
\text { frequency }\end{array}$ & $\begin{array}{l}\text { Good/bad } \\
\text { semantic } \\
\text { prosody }\end{array}$ \\
\hline the $1930 \mathrm{~s}$ & & & 1990 & & \\
\hline advanced & 1 & bad & paranoid & 4 & bad \\
\hline the $1950 \mathrm{~s}$ & & & unstable & 1 & bad \\
\hline worse-a & 1 & bad & intense & 1 & bad \\
\hline weak & 1 & bad & inspired & 1 & neutral \\
\hline incipient & 1 & bad & 2000 & & \\
\hline half-mad & 1 & bad & paranoid & 6 & bad \\
\hline the $1960 \mathrm{~s}$ & & & twitchy & 1 & bad \\
\hline paranoid & 2 & bad & hospitalized & 1 & neutral \\
\hline cataleptic & 2 & bad & & & \\
\hline ambulatory & 1 & neutral & & & \\
\hline paranoiac & 1 & bad & & & \\
\hline labeled & 1 & neutral & & & \\
\hline incurable & 1 & bad & & & \\
\hline homicidal & 1 & bad & & & \\
\hline functional & 1 & bad & & & \\
\hline \multicolumn{6}{|l|}{ the $1970 \mathrm{~s}$} \\
\hline paranoid & 4 & bad & & & \\
\hline complete & 1 & bad & & & \\
\hline chronic & 1 & bad & & & \\
\hline catatonic & 1 & bad & & & \\
\hline acute & 1 & bad & & & \\
\hline \multicolumn{6}{|l|}{ the $1980 \mathrm{~s}$} \\
\hline paranoid & 2 & bad & & & \\
\hline retarded & 1 & bad & & & \\
\hline
\end{tabular}


profiles of the terms denoting the mentally challenged

\begin{tabular}{lll}
\hline paranoiac & 1 & bad \\
labeled & 1 & bad \\
homicidal & 1 & bad \\
ever-splitting & 1 & bad \\
crazy & 1 & bad
\end{tabular}

Table 12: Adjectival collocates of schizophrenic (COHA)

The manual of mental disorders characterises schizophrenia as a mental disease with frequent delusions, disorganized speech, thinking and behaviour, leading to hallucinations (DSM-5 2013: 99).

Apart from severity degrees (e.g. advanced, chronic, incipient, severe schizophrenic) the collocates, both in GloWbE and COHA (see Table 11 and 12), suggest that schizophrenics tend to have paranoia fits together with visual and auditory sensations (e.g. ever-splitting, hallucinating, paranoiac, paranoid, sociopathic schizophrenic).

Generally, as far as the collocates of schizophrenic are concerned, they create a stereotyped portrayal of a diseased person (e. g. (19), (20) and (21)) and one might notice that it has not changed much throughout the 20th century (half-mad in the 1950s, homicidal in the 1960s, retarded, crazy in the 1980s, twitchy in the 2000s).

(19)Having once been labeled schizophrenic, there is nothing the pseudopatient can do to overcome the tag.

(20)In 1998, a paranoid schizophrenic vagrant living in a van on the street outside my house had become obsessed with my gardener, a pretty woman; one morning in late March, he had attacked her and stabbed her twenty-two times.

(21)Because what he said seemed incomprehensible, he was later diagnosed as a retarded schizophrenic.

(COHA)

The analysis of the corpora also shows that schizophrenics might be used in figurative meaning to denote an anxiety over something (e. g. cultural schizophrenics).

\section{Conclusion}

The present study showed that the change in attitudes towards the mentally challenged has been happening slowly but gradually throughout the $19^{\text {th }}-21^{\text {st }}$ centuries.

The corpus-based analysis resulted in the following observations:

1. As is seen from Table 13 negative semantic prosody still prevails in the analysed examples. The concordance lines available in the corpora, both GloWbE and COHA, indicate that the mentally challenged are still feared because of the stigma surrounding their disorders. Mental diseases, especially schizophrenia and those diseases which are thought to be genetically 
linked, are still associated with paranoia, sociopathy and potential danger to people surrounding an ill person.

\begin{tabular}{lll}
\hline$\#$ & Groups of the mentally challenged & Semantic prosody \\
\hline 1 & alcoholics & mostly bad, rarely neutral and good \\
2 & people with Alzheimer's disease & mostly bad, occasionally neutral \\
3 & anorexic & mostly bad, rarely neutral \\
4 & autistics & mostly bad or neutral, occasionally good \\
5 & people with bipolar disorder & mostly bad or neutral \\
6 & schizophrenic & mostly bad, rarely neutral \\
\hline
\end{tabular}

Table 13: Semantic prosody

2. There are remarkable tendencies which manifest themselves in prosody shifting. Thus, COHA indicates that starting from the 1980s-1990s the attitude towards certain groups of the mentally challenged has changed and a number of mental disorders have acquired neutral or even positive semantic prosody (e.g. Alzheimer's disease and autism). GloWbE, in its turn, shows that this tendency is near-universal and often takes place in the developed countries.

3. Judging by the number of the collocates available in GloWbE (e.g. in the case with autistics) considerably more attention is paid to the treatment of the mentally challenged people in the developed countries. This can be justified by the rapid development in medical science in these countries.

4. In three out of six cases under analysis the terms denoting the mentally challenged (anorexics, schizophrenics) or the disease itself (Alzheimer's disease) are sometimes used metaphorically to denote a lack of something, mass anxiety or confusion, e.g. financial anorexic, cultural schizophrenics or spiritual Alzheimer's. These cases indicate the tendency to relate the world of insanity to the normal world where the borderline between normal and abnormal in all the spheres, though rather vague, is defined by what is right and proper.

Further research could be conducted to elicit more peculiarities of the dichotomy sanity / insanity in English linguistic culture. As far as the corpus analysis is concerned, it is possible to describe overall semantic usage profiles realised in the collocational profiles of the mentally challenged. By doing so the researcher will have an opportunity to find new changing tendencies in the attitudes towards the mentally challenged.

\section{References}

Ayto, John (2005): Word Origins. The Hidden Histories of English Words from A to Z. London: A \& C Black.

BYU = the Brigham Young University corpora. http://corpus.byu.edu [10.12.2015]

Cardwell, Mike (1999): Dictionary of Psychology. London/Chicago: Fitzroy Dearborn.

Crano, William/Prislin, Radmila (2008): Attitudes and attitude change. New York: Psychology Press.

Davies, Mark (2012): "Expanding horizons in historical linguistics with the 400-million word Corpus of Historical American English". Corpora 7/2: 121-157.

Davies, Mark/Fuchs, Robert (2015): "Expanding horizons in the study of World Englishes with the 1.9 billion word Global Web-based English Corpus (GloWbE)". English WorldWide 36/1: 1-28. 
profiles of the terms denoting the mentally challenged

American Psychiatric Association (eds.) (2013): Diagnostic and Statistical Manual of Mental Disorders. DSM-5. Arlington, VA: American Psychiatric Association.

Fillmore, Charles (2003): "Double-decker definitions: The role of frames in meaning explanations". Sign Language Studies 3/3: 263-295.

Graedler, Anne-Line (2014): "Attitudes towards English in Norway: A corpus-based study of attitudinal expressions in newspaper discourse". Multilingua 33/3-4: 291-312.

Granger, Sylviane/Meunier, Fanny (2008): Phraseology. An interdisciplinary perspective. Amsterdam: Benjamins.

Hanks, Patrick (2013): Lexical Analysis: norms and exploitations. Cambridge/Mass.: MIT Press.

MHA = Mental Health America (2015): Paranoia and Delusional Disorders. http://www.mentalhealthamerica.net/conditions/paranoia-and-paranoid-disorders [12.12.2015].

NSDUH = National Survey on Drug Use and Health in the USA (2015): Population Data / NSDUH. http://www.samhsa.gov/data/population-data-nsduh [10.12.2015].

OED = Oxford English Dictionary (2014): The definitive record of the English language. http://www.oed.com [25.12.2015].

Partington, Alan (1998): Patterns and meanings. Amsterdam: Benjamins.

Putnam, Hilary (1975): Mind, Language and Reality. Cambridge: Cambridge University Press. (= Philosophical Papers 2).

Schomerus, Georg et. al. (2010): "The Stigma of Alcohol Dependence Compared with Other Mental Disorders: A Review of Population Studies”. Alcohol Alcohol 46/2: 105-112. doi: 10.1093/alcalc/agq089.

Sinclair, John (1987): Looking up. An account of the COBUILD project in lexical computing and the development of the Collins COBUILD English language dictionary. London: Collins.

Stubbs, Michael (1996): Text and Corpus Linguistics. Computer-assisted studies of language and culture. Oxford etc.: Blackwell. 